\title{
Investigation of the deposition behaviour and antibacterial effectivity of allicin aerosols and vapour using a lung model
}

\author{
JANA REITER ${ }^{1}$, JAN BORLINGHAUS ${ }^{1}$, PHILIPP DÖRNER ${ }^{2}$, WOLFGANG SCHRÖDER ${ }^{2}$, \\ MARTIN C.H. GRUHLKE ${ }^{1}$, MICHAEL KLAAS ${ }^{2}$ and ALAN J. SLUSARENKO ${ }^{1}$ \\ ${ }^{1}$ Department of Plant Physiology (Bio3), RWTH Aachen University; ${ }^{2}$ Institute of Aerodynamics, \\ RWTH Aachen University, D-52074 Aachen, Germany
}

Received July 24, 2019; Accepted September 25, 2019

DOI: $10.3892 / e t m .2019 .8387$

\begin{abstract}
Allicin is a natural antibiotic produced by garlic as a defence against pathogens and pests. Due to the worldwide increase in antibiotic resistance, new antibiotics are desperately required. Allicin is such a candidate and is active against several multidrug-resistant (MDR) strains of human pathogens, including methicillin-resistant Staphylococcus aureus (MRSA). When administered orally, allicin is titrated out by glutathione in the cells and blood, and effective therapeutic concentrations are difficult to achieve at the site of an infection. However, in the case of lung infections, allicin can be delivered directly to pathogens via the pulmonary route. In this study, we designed and constructed an in vitro lung test rig, which allowed us to model accurately the exposure of lung air-passage surfaces to allicin and gentamicin, in order to examine the feasibility of combating lung infections by direct inhalation. A prototype test rig of lung bronchi with three bifurcations was constructed, which could be coated internally with a thin layer of bacteria-seeded agar medium. The deposition of antimicrobial aerosols on the modelled bronchial surfaces was followed in preliminary tests without the need for animal experiments. The differential sensitivity of the test bacteria to different antibiotics and the dose-dependency of inhibition was shown using the model. Furthermore, a synergistic effect of allicin vapour and ethanol in inhibiting bacterial growth was demonstrated. The modelling of the axial velocity air-flow distribution correlated with the regions indicating the inhibition of bacterial growth, demonstrating that the model has predictive value and can reduce the requirement for animal sacrifice in pre-clinical trials of novel antibiotics.
\end{abstract}

Correspondence to: Dr Alan J. Slusarenko, Department of Plant Physiology (Bio3), RWTH Aachen University, Worringerweg 1, D-52074 Aachen, Germany

E-mail: alan.slusarenko@bio3.rwth-aachen.de

Key words: lung infection, antibiotic resistance, aerodynamic modelling, bacterial inhibition

\section{Introduction}

Natural defence compounds, such as the antibiotic substance, allicin (diallylthiosulfinate), are produced by garlic tissues when the cells are damaged (1-3). Allicin can be easily synthesized in the laboratory by an oxidation of diallyl disulphide (DADS) (4). The substrate for allicin biosynthesis is $S$-allyl-L-cysteine sulfoxide, an odourless non-toxic non-protein amino acid found in the cytosol of garlic cells (5). The enzyme, alliin lyase (alliinase, E.C.4.4.1.4), is present in the cell vacuole and hydrolyses alliin to dehydroalanine and allylsulfenic acid. Two molecules of allylsulfenic acid condense spontaneously to produce one molecule of allicin (Fig. 1).

Allicin crosses cell membranes easily and reacts with thiol groups in glutathione (GSH) and accessible cysteines in proteins to yield $S$-thioallylmercapto derivatives (6-10). Allicin has been shown to have pronounced antimicrobial activities against multiple drug-resistant (MDR) human lung pathogens (11). The effects of allicin on bacterial proteins have been well documented $(10,12)$ and a recent study identified a series of proteins $S$-thioallylated by allicin in human cells in culture (13). However, as allicin is rapidly titrated out by GSH and metabolized in the human body, the bioavailability of allicin per se following consumption is generally low (14). Thus, any attempts to use allicin to combat microbial infections encounter the obstacle of achieving therapeutic concentration at the site of infection, particularly if allicin is administered orally or is injected into the blood $(15,16)$. The direct inhalation of allicin vapour or aerosols potentially offers an immediate route for the treatment of lung pathogens which would avoid these drawbacks. Indeed, there is a historical precedent from the pre-streptomycin era reporting a high success rate for treating tuberculosis in patients by inhaling the vapour from crushed garlic pulp held in a specially designed inhaler (17) (Fig. 2). An enlightening summary of these studies has been reported by Block (2). Moreover, allicin has been shown to have antimicrobial activity against several human lung pathogenic bacteria (11). The development of allicin-inspired fluoroquinolones, such as antibacterials against Enterococcus faecium, Staphylococcus aureus, Klebsiella pneumoniae, Acinetobacter baumannii, Pseudomonas aeruginosa and 
Enterobacter spp. (ESKAPE) pathogens was also recently reported (18).

The emergence of bacteria exhibiting multiple resistance to antibiotics in current clinical use is an increasing threat to the effective treatment of infectious diseases. Frequently, resistance emerges rapidly following the discovery of an antibiotic, particularly after its introduction into clinical practice $(19,20)$. There have been few new classes of antibiotics discovered since the 1970s and novel antibiotics are desperately required $(21,22)$. MDR strains of lung pathogenic bacteria, such as Pseudomonas aeruginosa, Streptococcus pneumoniae, Staphylococcus aureus, Acinetobacter baumannii and Mycobacterium tuberculosis have been reported and lung infections are becoming increasingly difficult to treat (23-27). New categories of antibiotics with multiple sites of action, such as allicin, are particularly desirable as they are likely to render the emergence of resistance more difficult.

Any novel antibiotic compounds require testing in pre-clinical trials, which out of necessity, involve costly and extensive animal studies. It is desirable to know as much as possible about the behaviour of a test substance before progressing to animal trials and in this regard, in this study, we designed and constructed a test rig that accurately recapitulates the air-flow through the life-size 2nd, 3rd, 4th and 5th bronchi of a human lung in order to help characterize the behaviour of inhaled antibiotics. The detailed construction and aerodynamic characteristics of air-flow in this model have been previously reported (28). Herein, we report that using this model, it is possible to demonstrate the dose-dependent efficacy of gentamicin aerosols, and allicin aerosols and vapour. Moreover, differences in the susceptibility of bacteria to the antibiotics were demonstrated in the model and synergism for the inhibitory effect to bacteria was revealed between ethanol and allicin in the gas phase. Therefore, initial proof of principle for using the lung model to predict the behaviour of antibiotics supplied to the lungs has been shown, and it seems that some clinically relevant questions can be addressed using the test rig prior to clinical trials, which will reduce the need for some animal experiments.

\section{Materials and methods}

Allicin synthesis and application. Allicin was synthesized by the oxidation of DADS with $\mathrm{H}_{2} \mathrm{O}_{2}$ as described previously (4).

Bacteria. The E. coli strain, MegaX DH10B T1R (Invitrogen/Thermo Fisher Scientific), was transformed with either the empty vector pRU1097 (=allicin-susceptible E. coli strain) or with pRU1097 containing a $9 \mathrm{~kb}$ allicin resistance-conferring genomic clone from an allicin-resistant Pseudomonas fluorescens isolated from a garlic bulb (=allicin-resistant E. coli strain) (29). As the pRU1097 vector (30) carries a gentamicin resistance gene as a selectable marker, both transformant lines have high gentamicin resistance.

Lung model. The construction details of the lung model have been previously reported (28). The lung model represents the 2 nd to 5 th generation (the trachea $=0$ th generation) of average life-size bronchial passages in a human lung (Fig. 3A). The
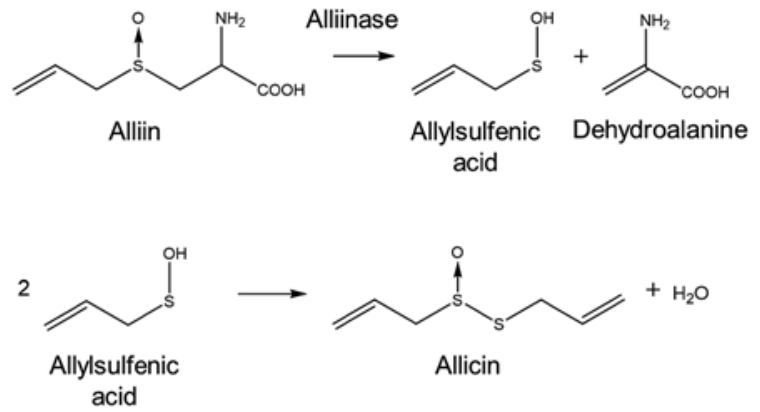

Figure 1. The production of allicin by the action of alliinase on $(2 R)$-2-amino-3-[(S)-prop-2-enylsulfinyl]propanoic acid (common name alliin, also known as $S$-allyl-L-cysteine sulfoxide).

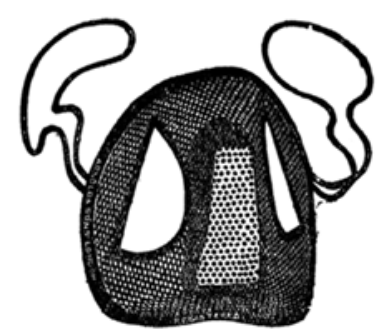

Figure 2. Minchin's specially designed inhaler for use with crushed garlic preparations in the treatment of pulmonary tuberculosis [image reproduced from Minchin (17)].

model is approximately $10 \times 10 \mathrm{~cm}$. The inner coating of agar medium simulates the epithelial surface of the bronchi and allows for the incorporation of bacteria to simulate an infected lung. In the agar-coated model, the internal diameter of the initial bronchus is $8.3 \mathrm{~mm}$ and the internal diameter of the 5 th bronchus is $3.5 \mathrm{~mm}$. The agar-coated bronchi were prepared in two halves, which were subsequently positioned together with the help of locating pins and screw clamps to make the bronchial tubes.

The casting process of the bronchial-surface coating of bacteria-seeded agar was performed using a negative mould with a positive stamp with an offset of $1 \mathrm{~mm}$ (Fig. 4). The mould and stamp were turned from blocks of polyoxymethylene (POM) with a milling machine. Before the agar surface was cast, the surfaces were sterilized by UV light under a clean bench (Labgard ${ }^{\circledR}$ Class II NU-437-500E, NuAir) for 20 min. The Luria-Bertani (LB) medium with the addition of $1.5 \%(w / v)$ agar (Agar-Agar Kobe I, powdered, for microbiology, Carl Roth) was autoclaved for $20 \mathrm{~min}$ at $121^{\circ} \mathrm{C}$ and subsequently tempered in a water bath at $50^{\circ} \mathrm{C}$ prior to use. A $300 \mu 1$ aliquot of bacterial suspension from a log phase culture grown to an optical density of 0.2 at wavelength $600 \mathrm{~nm}$ $\left(\mathrm{OD}_{600}=0.2\right)$ was mixed with a $20 \mathrm{ml}$ aliquot of agar tempered to $50^{\circ} \mathrm{C}$ and was rapidly filled into the mould. Immediately afterwards, the stamp was pushed down by the precise positioning of dowel pins (Fig. 4). The stamp was held for $5 \mathrm{~min}$ to ensure complete agar solidification. Subsequently, the stamp was removed and excess medium at the inlet and outlets was trimmed off with a scalpel to obtain sharp inlet and outlet contours. This procedure was repeated for the other half of the mould before both halves were assembled to yield the model bronchial system. 

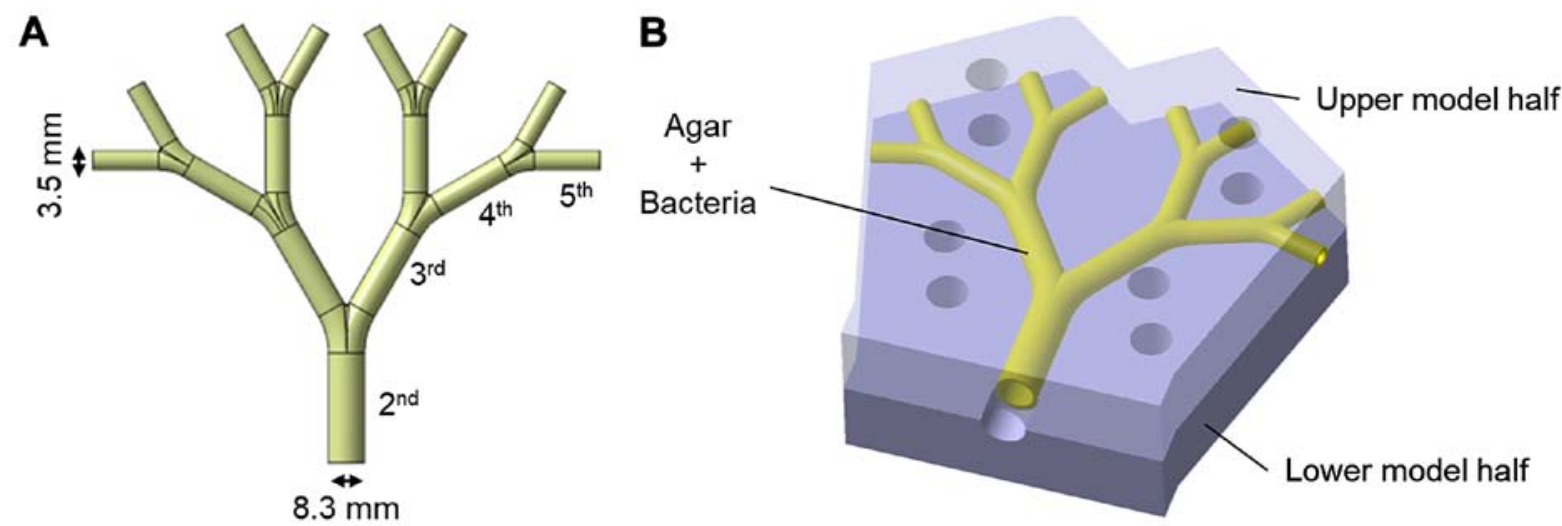

Figure 3. (A) The lung model of the 2 nd to 5 th human bronchial passages in life size. (B) The model is composed of two identical halves, the inner surface of the tubes is cast with $1 \mathrm{~mm}$ thick bacteria-containing agar-medium to simulate an infected lung.

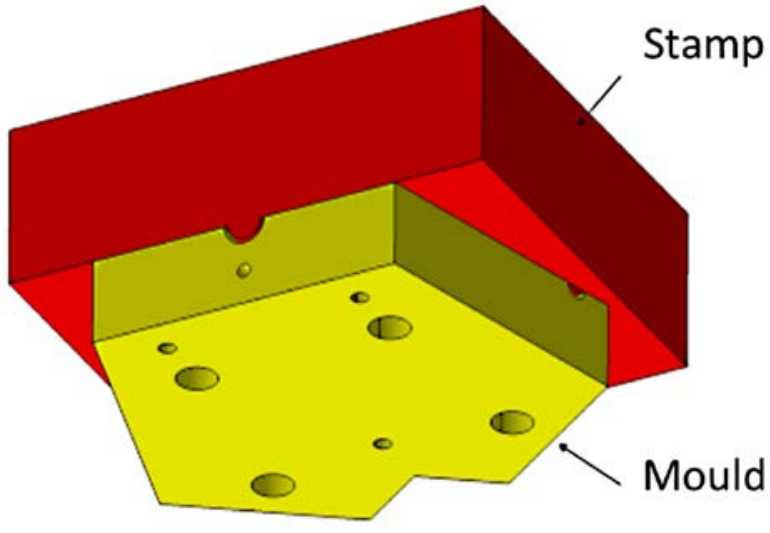

Figure 4. Using a stamp and mould allows the lung model casting with a 1-mm-thick bacteria-seeded agar film in each half of the symmetrical lung model.

The assembled agar-coated bronchial passages within the upper and lower mould halves was then placed in the incubation chamber and attached to the aerosol-generator and air supply (Fig. 5). A TurboBOY SX with the PARI LC SPRINT nebuliser nozzle attachment (Pari $\mathrm{GmbH})$ was used to generate the aerosol particles. According to the manufacturer, this set-up produces aerosol particles with the mass median diameter (MMD) of $3.5 \mu \mathrm{m}$ with mass percentage below $5 \mu \mathrm{m}$ $67 \%$ and total output rate of $600 \mathrm{mg} / \mathrm{min}$ (measured with $0.9 \%$ $\mathrm{NaCl}$ solution and $20 \mathrm{l} / \mathrm{min}$ inspiratory flow). The nebulizer was attached to the compressor and external air-supply and pressure gauge. The air-supply was set to $6 \mathrm{l} / \mathrm{min}$ and the compressor delivered $5 \mathrm{l} / \mathrm{min}$ and this provided in total, $11 \mathrm{l} / \mathrm{min}$ air-flow entering the lung model via the long inlet tube with an internal diameter of $8.3 \mathrm{~mm}$ (Fig. 5). The inlet tube connected seamlessly with the agar-coated lung model and ensured a uniform laminar air-flow into the model.

The temperature in the incubator chamber was regulated by a copper heating plate with aluminium cooling fins attached and on-off settings at 36.5 and $37.5^{\circ} \mathrm{C}$, respectively. The thermostat temperature sensor was located at the upper edge of the long side of the incubator and air was circulated within the chamber by means of a fan placed $1 \mathrm{~cm}$ from the heating plate. A $1.5 \mathrm{~cm}$ diameter air outlet from the incubation chamber was fitted with a $0.45 \mu \mathrm{m}$ bacteria filter.
Treatment. For aerosol treatment, allicin or gentamicin solutions (diluted in deionised water) were used. The allicin solutions were prepared from stock solutions and the concentrations were confirmed by high-performance liquid chromatography (HPLC) as previously described (4). For the treatment with allicin vapour, allicin was diluted in $95 \%$ ethanol and placed into a shallow plastic vessel to yield a $5 \mathrm{~cm}^{2}$ surface for evaporation at room temperature into the gas phase. Following treatment, the residual volume of allicin solution was measured and the concentration was determined by HPLC. The quantity of allicin entering the lung model over the period of the treatment could be calculated from the residual allicin solution.

Visualization of bacterial growth and growth inhibition. At the end of an experiment, and after the air-flow was discontinued, the lung model assembly was taken out of the incubation chamber and after covering with moist filter paper, was wrapped in aluminium foil and incubated at $37^{\circ} \mathrm{C}$ for $18 \mathrm{~h}$ to allow for bacterial growth. The apparatus was then dismantled and separated, exposing the inner surfaces of the two halves of agar tubes representing the bronchi. The halves were sprayed with $0.5 \%$ 3-(4,5-dimethylthiazol-2-yl)-2,5diphenyltetrazolium bromide (MTT) solution, covered with transparent polyethylene foil and incubated at $37^{\circ} \mathrm{C}$ for $30 \mathrm{~min}$. Metabolically active bacteria reduced the MTT to dark coloured formazan and where bacteria were inhibited, the agar remained pale.

\section{Results}

The detailed modelling of the test rig has been previously described (28). The qualitative axial velocity distribution through the bronchi is shown as a spectral heatmap in Fig. 6. High air-flow velocities are at the red end of the visible colour spectrum and low air-flow velocities at the blue end. The highest velocities were at the inner surface of the carinal surfaces after the branch points. Low velocity 'shadow areas' are also apparent, especially at the outer edge at the first dichotomy.

Visualization of bacterial growth. A non-pathogenic E. coli strain (MegaX DH10B ${ }^{\mathrm{TM}}$ T1R transformed with empty 


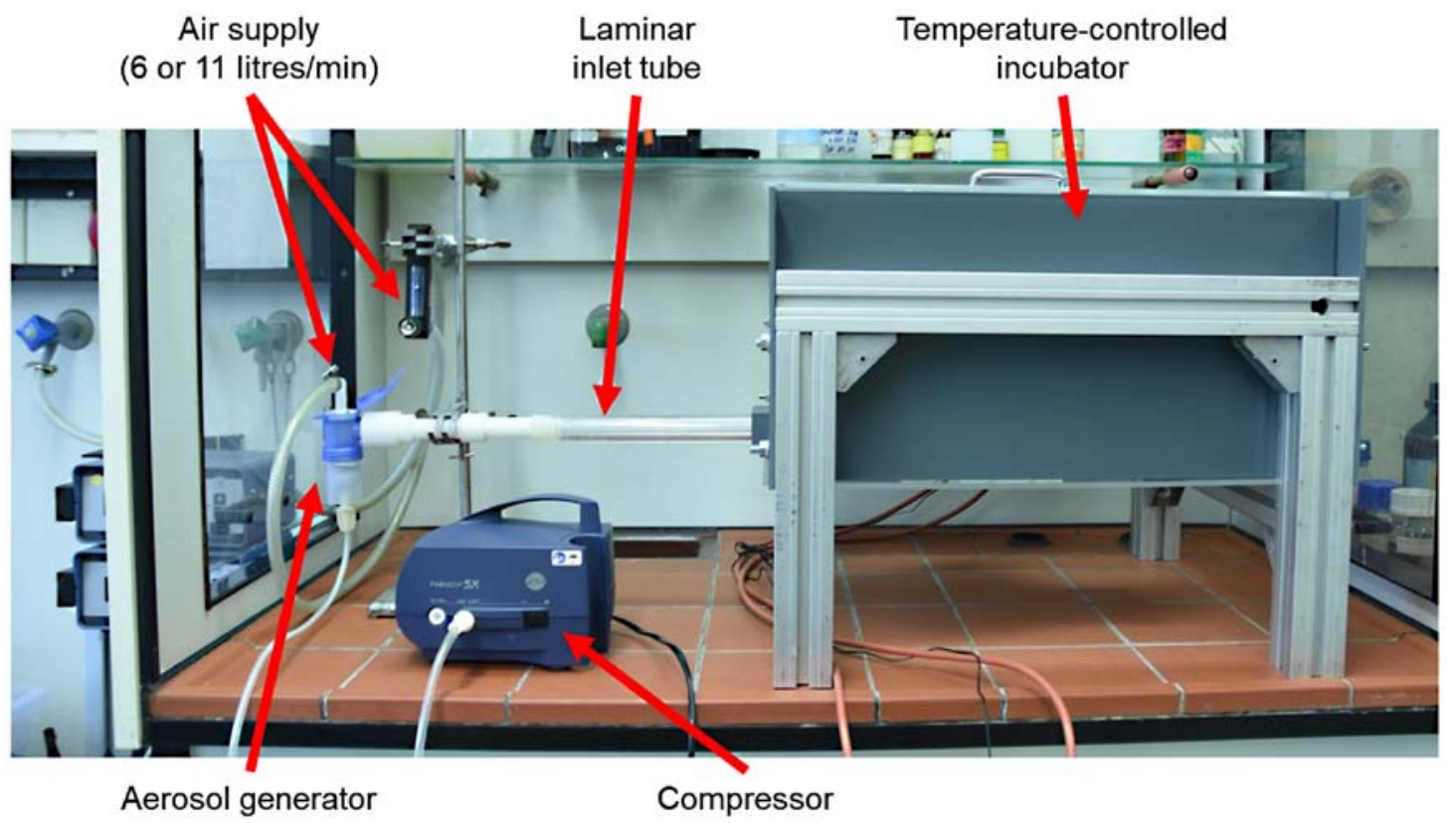

Figure 5. The experimental set-up. The lung-model assembly was placed into a ventilated temperature-controlled incubator and connected to a laminar inlet tube. The inlet tube was connected to the aerosol generator attached to the compressor to produce the aerosol. A further inlet at the top of the aerosol generator allowed air-flow through the model to be regulated via a compressed air-supply. The whole apparatus was placed in a fume hood.

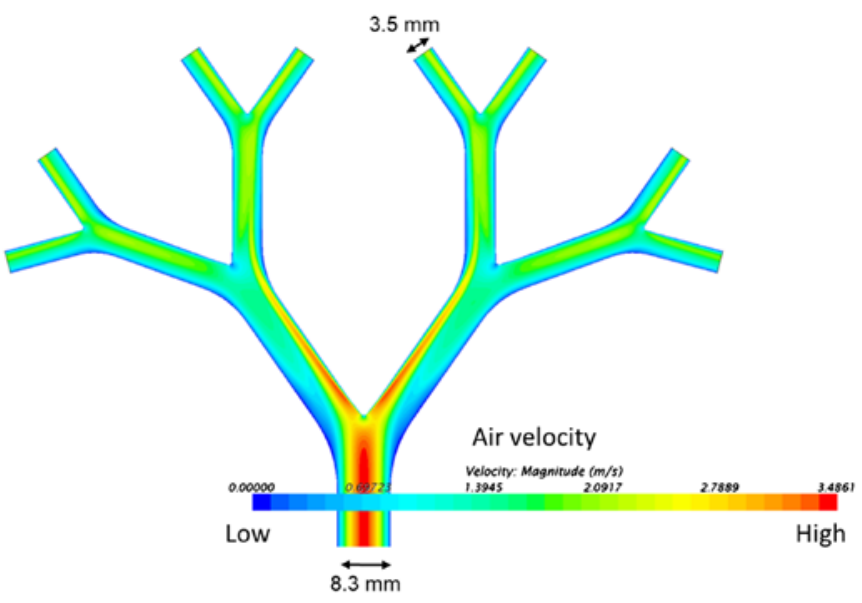

Figure 6. Modelling of qualitative axial velocity distribution through the test-rig shown as a spectral heat map.

pRU1097 vector) was used for the characterization of the behaviour of the test rig in the experiments reported in this study, as research with human pathogens demands particularly stringent containment conditions in specialized facilities. The feasibility of showing bacterial growth and growth inhibition within the bronchi of the lung model by spraying the surface with MTT was tested by killing bacteria with sterilizing UV radiation in a specific pattern (Fig. 7). The parts of the model shaded by aluminium foil (Fig. 7A) to protect them against UV-exposure exhibited purple-black colouration after spraying with MTT, indicating the existence of metabolically active bacteria. By contrast, the UV-exposed areas of the model where bacteria had been killed, remained colourless (Fig. 7B). Moreover, the versatility of the system was demonstrated by using various amounts of $E$. coli suspension incorporated in the agar layer ( 300 or $600 \mu \mathrm{l}$ of suspension with $\mathrm{OD}_{600}=0,2$ per $20 \mathrm{ml} \mathrm{LB}$-agar) and showing that the cell density correlated with the intensity of colour development after spraying with MTT solution (Fig. 8). This parameter can be optimized for individual bacterial test species.

Aerosol deposition and dose-dependency of bacterial inhibition with test antibiotics. Using an air-flow rate of $11 \mathrm{l} / \mathrm{min}$ and a 20 min flow time as the standard, the effect of increasing the concentration of allicin solution in the aerosol was tested. At $0.25 \mathrm{mM}$ allicin, no growth inhibition of allicin-susceptible E. coli strain (E. coli MegaX DH10B ${ }^{\mathrm{TM}}$ T1R transformed with empty pRU1097 vector) was detected; however, at $0.5 \mathrm{mM}$ allicin, a clear inhibition of bacterial growth on the bronchial surfaces at the carinal branch points was observed (Fig. 9). This presumably reflects the areas of maximum aerosol deposition and coincides with areas of locally high air-flow velocities (Fig. 6). With an aerosol of $1 \mathrm{mM}$ allicin, the growth inhibition of allicin-susceptible $E$. coli strain was complete on all the bronchial surfaces throughout the model (Fig. 9). In total, $8 \mathrm{ml}$ of the allicin test solution were passed through the model as an aerosol, meaning that the amounts of allicin aspirated through the model were $0.33,0.65$ and $1.2 \mathrm{mg}$, respectively. However, it still has to be investigated in further measurements what proportion of the aerosol was deposited on the surfaces and what proportion remained suspended in the transient air-flow.

The usefulness of the lung model in highlighting the differential resistance of bacteria to antibiotics is shown in Fig. 10. The dose-dependency of growth inhibition of the allicin-susceptible E. coli isolate (MegaX DH10B ${ }^{\mathrm{TM}}$ T1R) with the empty pRU1097 vector (30) was compared to bacteria made resistant to allicin by transforming $E$. coli with the recombinant pRU1097 vector containing an allicin-resistance-conferring genomic clone from an allicin-resistant 

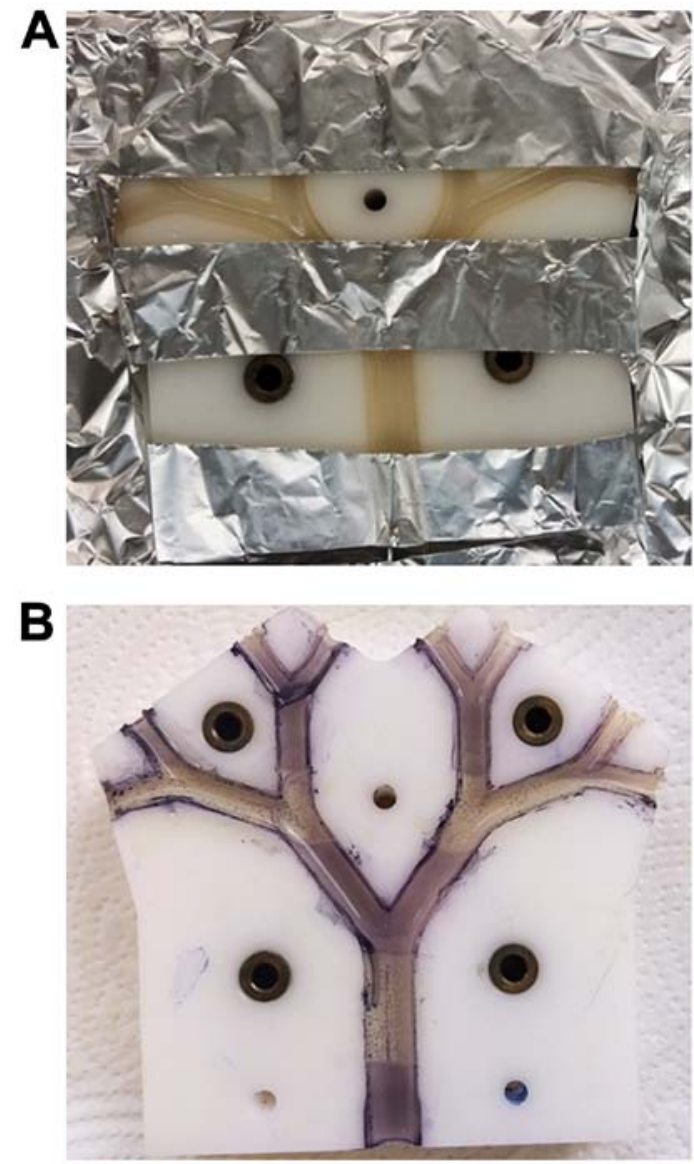

Figure 7. Proof of principle of MTT colouration as a reporter for bacterial growth. (A) The top cover was removed from the seeded-agar lung model, which was partially covered with aluminium foil and then exposed to a sterilizing UV light source for $20 \mathrm{~min}$, and incubated for $18 \mathrm{~h}$ at $37^{\circ} \mathrm{C}$ to allow growth of the embedded E. coli MegaX DH10B ${ }^{\text {TM }}$ T1R cells (transformed with empty pRU1097 vector). (B) The two halves of the model were then separated and sprayed with MTT solution and incubated for a further $30 \mathrm{~min}$ at $37^{\circ} \mathrm{C}$. The pale stripes where bacteria were killed by UV radiation can be seen against the purple-black colouration where bacteria were shaded from exposure to UV radiation by the aluminium foil.

Pseudomonas fluorescens strain isolated from garlic (29). The growth of the susceptible $E$. coli strain (empty vector control) was completely inhibited throughout the lung model by a $1 \mathrm{mM}$ allicin aerosol, whereas the allicin-resistant genomic clone transformant exhibited only slight inhibition at the carinal surfaces of the first branch point. With an aerosol of $2 \mathrm{mM}$ allicin, the inhibition of the resistant $E$. coli extended to the carinal surfaces of the 2nd and 3rd branch points and at $5 \mathrm{mM}$ inhibition, it was complete over all the bronchial surfaces (Fig. 10A and B). This differential resistance was specific to allicin, as was shown by comparing the inhibition of the two E. coli strains to gentamicin. The pRU1097 vector carries gentamicin resistance as a selection marker and both the empty vector and the $E$. coli genomic clone transformants were equally susceptible to gentamicin aerosols over the 2-15 mM range (Fig. 10C). This observation, that the differential resistance of bacteria to antibiotics can be demonstrated in the simulated bronchial environment of the model, holds promise for the development of allicin, either alone or in combination with other antibiotics, for the treatment of actual lung diseases, including MDR strains.
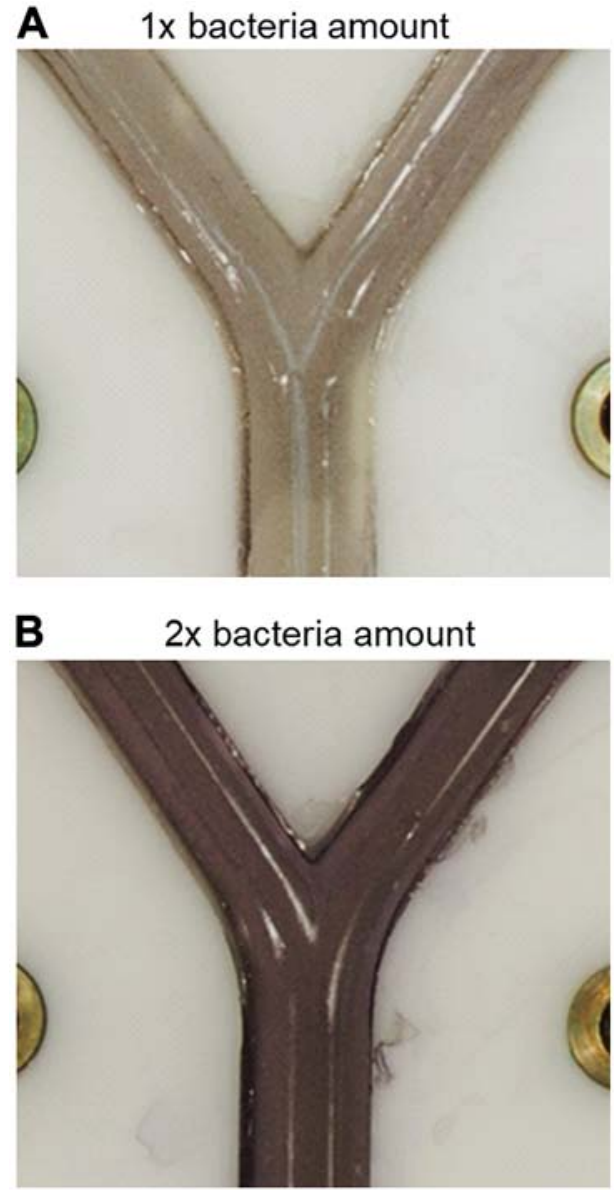

Figure 8. Effect of bacterial density in the seeded agar on colour development with MTT. (A) $300 \mu 1$ or (B) $600 \mu 1$ E. coli MegaX DH10B ${ }^{\mathrm{TM}}$ T1R cells $\left(\mathrm{OD}_{600}=0.2\right.$, transformed with empty pRU1097 vector $)$ were incorporated in $20 \mathrm{ml}$ LB-agar.
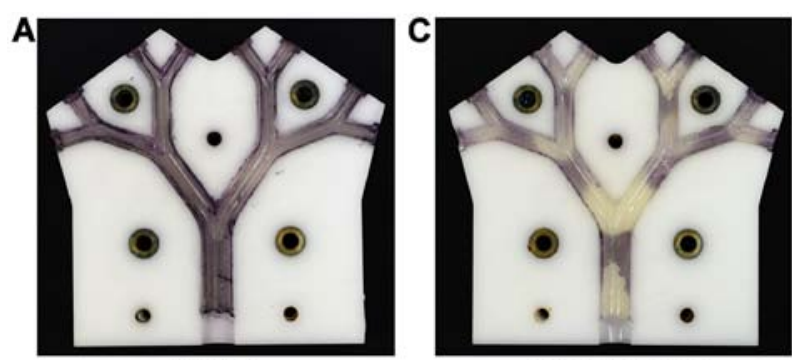

Water

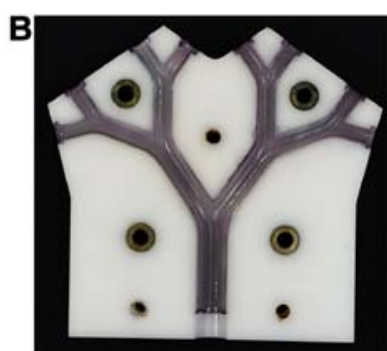

$0.25 \mathrm{mM}$ allicin

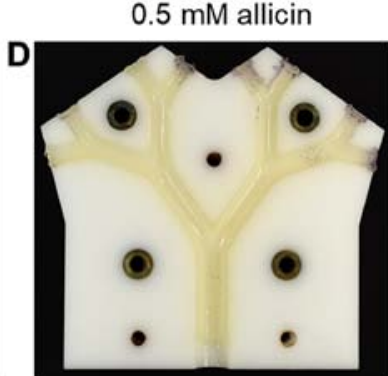

$1.0 \mathrm{mM}$ allicin
Figure 9. Demonstration of aerosol deposition pattern and dose-dependency of inhibition of bacterial growth by allicin (allicin-susceptible E. coli MegaX DH10B $^{\text {TM }}$ T1R cells transformed with empty pRU1097 vector). (A) Water or (B-D, 0.25, 0.5 and $1.0 \mathrm{mM}$, respectively) the allicin aerosol was aspirated through the lung model at $11 \mathrm{l} / \mathrm{min}$ for $20 \mathrm{~min}$. Inhibition of bacterial growth was seen at $0.5 \mathrm{mM}$ allicin aerosol mainly at the bronchial surfaces around the carinal branch points. At $1 \mathrm{mM}$ allicin aerosol inhibition was complete over all the bronchial surfaces. 

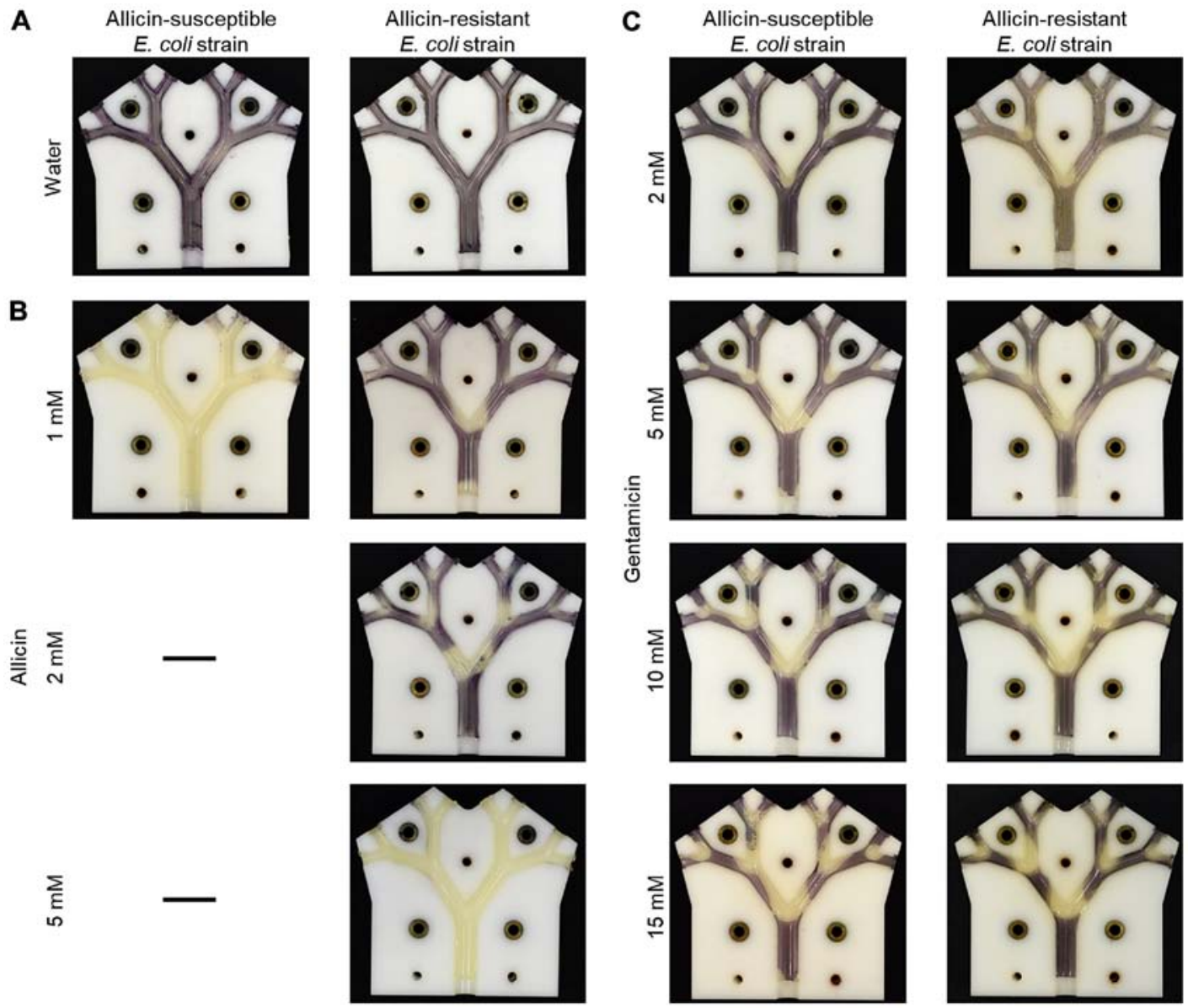

Figure 10. Demonstrating differential allicin-susceptibility between bacterial strains. The allicin-susceptible E. coli strain (E. coli MegaX with empty pRU1097 vector) was compared to allicin-resistant $E$. coli strain (E. coli MegaX with pRU1097-clone 1 vector containing an allicin-resistance-conferring genomic clone). (A) The treatment with water did not lead to bacterial growth inhibition. (B) The differential sensitivity of the bacteria observed with allicin was not observed with (C) gentamicin, where an equal dose-dependency of inhibition of the empty vector and allicin-resistant isogenic $E$. coli strains was observed.

Synergism between ethanol and allicin vapour. As allicin evaporates into the gas phase, an alternative to supplying it as an aerosol via the pulmonary route, would be to breathe in allicin molecules as a vapour. The efficacy of allicin vapour against allicin-susceptible $E$. coli was tested in the lung model. In these experiments, $2 \mathrm{ml}$ of test solution with an exposed surface area of $5 \mathrm{~cm}^{2}$ had air passed over it through the lung model at $6 \mathrm{l} / \mathrm{min}$. Neither the vapour from $42 \mathrm{mM}$ allicin in aqueous solution, nor from $95 \%$ (v/v) ethanol caused any visible inhibition of $E$. coli growth following $40 \mathrm{~min}$ of treatment (Fig. 11A and B). The concentration and volume of the allicin solution remaining at the end of the experiment were measured and the values were used to calculate the amount of allicin, which had evaporated into the gas flow during the experiment. In the case of the $42 \mathrm{mM}$ allicin solution, $1.27 \mathrm{mg}$ of allicin had entered the gas phase and had passed through the model in a 40-min period. By contrast, a weaker $18.6 \mathrm{mM}$ solution of allicin in $95 \%$ ethanol caused the inhibition of E. coli growth after only $20 \mathrm{~min}$ 'inhalation' (Fig. 11C). In the latter case, only $0.45 \mathrm{mg}$ of allicin vapour had passed through the lung model. The degree of inhibition of E. coli growth increased progressively after 30 and 40 min of treatment with the vapour from the $18.6 \mathrm{mM}$ ethanolic allicin solution, and by $40 \mathrm{~min}$ inhibition, was virtually complete (Fig. 11D and E). The 30- and 40-min 'inhalations' corresponded to $0.9 \mathrm{mg}$ and maximally
$6.0 \mathrm{mg}$, respectively, of allicin vapour passing through the lung model. There is some uncertainty as to the amount of allicin entering the vapour phase for the 40-min time point as under these conditions, the remainder of the $2 \mathrm{ml}$ of solution had dried to a residue that could not be accurately quantified. The value of a maximum $6.0 \mathrm{mg}$ would be correct if all the allicin in the original $2 \mathrm{ml}$ solution had entered the vapour phase. Allicin has a high relative molecular mass $\left(M_{\mathrm{r}}=162.28\right)$ and is quite polar; thus, its vapour pressure $(P)$ is relatively low; however, it is not easy to determine as it decomposes at the high temperatures needed to determine $P$ experimentally. The results for the 20- and 30-min 'inhalation' periods clearly demonstrated a pronounced synergism between allicin and ethanol in the vapour phase in the inhibition of $E$. coli growth.

\section{Discussion}

In the case of lung infections, the delivery of antibiotics via the pulmonary rather than the oral route would seem advantageous for a number of reasons. Most importantly, the pulmonary route provides direct exposure of the antibiotic to the pathogen and does not rely on assimilation into the body and circulatory transport to achieve a therapeutic dose at the site of treatment. Moreover, for a substance, such as allicin from garlic, the oral route is in any case unrealistic as allicin will be very rapidly 

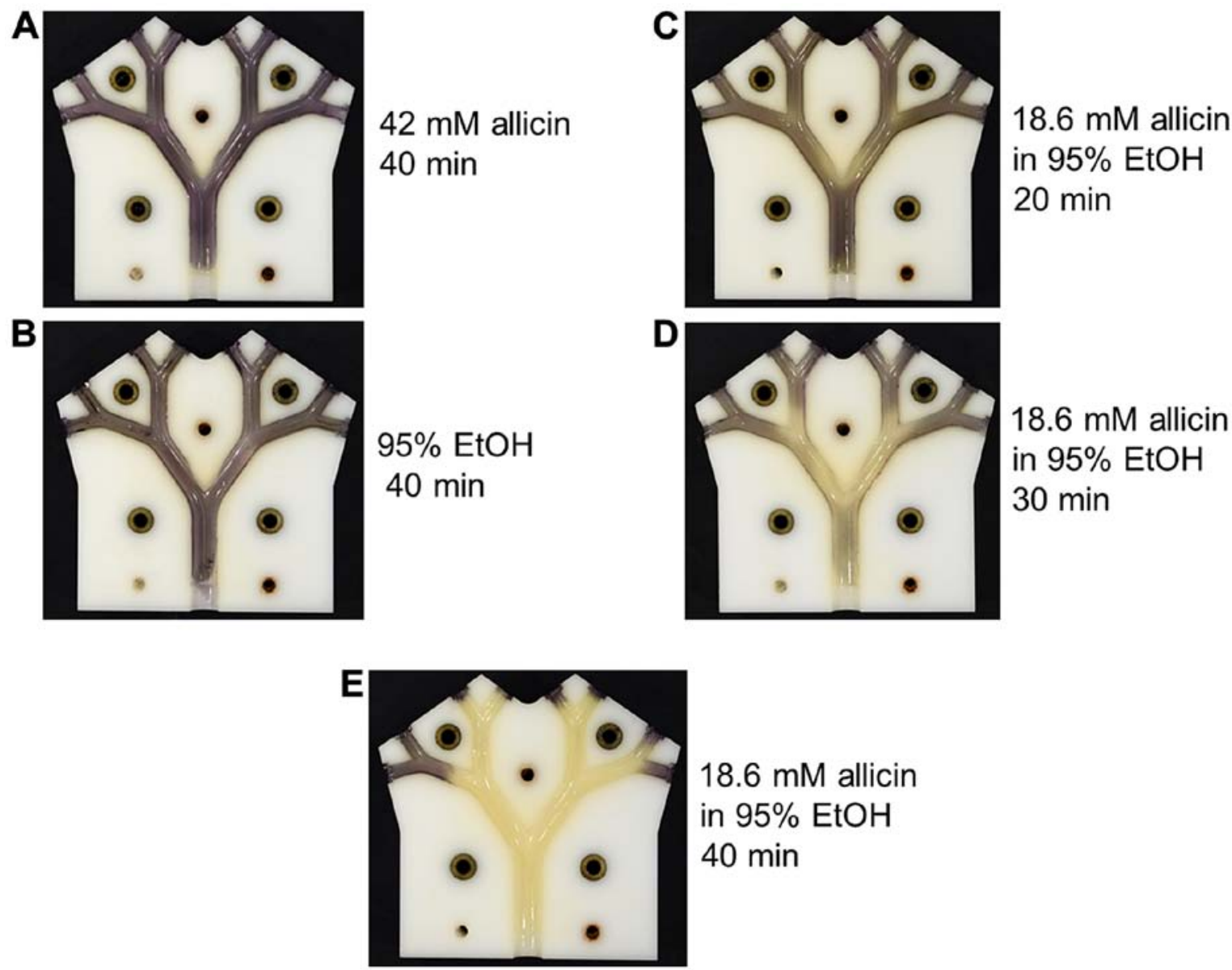

Figure 11. The synergistic effect of ethanol as a solvent for the antibacterial effectivity of allicin vapour. (A) $2 \mathrm{ml} 42 \mathrm{mM}$ allicin for $40 \mathrm{~min}$. (B) $2 \mathrm{ml} 95 \%$ ethanol for $40 \mathrm{~min}$. (C-E) $2 \mathrm{ml} 18.6 \mathrm{mM}$ allicin $95 \%$ ethanol for 20,30 and $40 \mathrm{~min}$, respectively. In all cases the surface area for evaporation was $5 \mathrm{~cm}^{2}$ and the air-flow rate was $61 / \mathrm{min}$.

titrated out by glutathione with which it reacts readily to form $S$-allyl-mercapto-glutathione $(6,7,14,31,32)$. Antibiotics can be delivered directly into the lungs either as an aerosol of droplets or as molecules in the gas phase as a vapour. Aerosols would be required for most of the conventional antibiotics as they are not volatile and do not enter the gas phase directly. Allicin, however is volatile, as attested to by the odour, it evaporates into the air by crushing or cutting garlic cloves. Nevertheless, due to its relatively large size and high polarity, its vapour pressure is not high. The efficacy of allicin aerosols and allicin vapour against $E$. coli were investigated in this study using the lung model. The ability of allicin and other thiosulfinates to inhibit bacteria, including lung pathogenic bacteria, as a vapour has been demonstrated in static Petri plate assays $(11,31)$. The development of allicin as an antibiotic for clinical use is not completely straightforward, as although it can be easily synthesized (4), is not stable in solution for long periods of time unless it is frozen (33). Moreover, allicin is also inhibitory to mammalian cell growth in a dose-dependent manner $(11,34)$. Furthermore, tissue burns from the inappropriate use of garlic preparations in attempts to treat various conditions have been well documented (2). Therefore, it remains to be determined whether there is a sufficient degree of differential toxicity between mammalian cells and the target microbes in each given situation to warrant the use of allicin as a treatment for infections. However, in this regard, it should be remembered that cells cultured in vitro are likely to be more sensitive than cells in vivo, where a continual supply of GSH in bodily fluids will help to protect them against allicin $(11,31)$. For example, cells in the lung are continually supplied with blood and bathed with epithelial lining fluid (ELF) containing GSH in the $\mathrm{mM}$ range $(35,36)$. Moreover, by virtue of their function in oxygen uptake, lung cells must be well protected against oxidative stress. With a substance, such as allicin which has an oxidative mechanism of action, GSH protects cells against the effects of allicin. Cells in culture, with only a fixed charge of GSH in the medium, will probably be more sensitive to allicin than cells in vivo which are continually bathed with new GSH which titrates out allicin. Bacteria colonizing the lung surface would be more immediately exposed to allicin than the underlying epithelial cells and this might be expected to contribute to a differential sensitivity of epithelial cells and bacteria the in vivo situation in lung disease (11). In this regard, the historical report of Minchin of the successful treatment of pulmonary tuberculosis with vapour from garlic pulp is significant (17). It should be noted that aerosols of allicin solutions could be potentially much more damaging to lung tissue than allicin vapour and this aspect must be carefully investigated before allicin can be used therapeutically. These speculations aside, at some point, the efficacy of allicin against lung pathogens must be tested in an animal model to address these unknowns directly. However, a number of potential treatment 
parameters can be determined in vitro using the lung test rig in pre-clinical trials and can thus reduce the number of animal experiments necessary.

A further difficulty for developing novel antibiotics is the emergence of resistance. Even though an antibiotic, such as allicin with multiple sites of action makes the appearance of spontaneous resistance in microbes difficult, it does not mean that it cannot occur, particularly under prolonged and severe selection pressure. Thus, high resistance against allicin has been found in some naturally occurring bacteria living in association with garlic and presumably facing a high selection pressure against allicin (29).

The test rig is scaled to cover the 2nd to 5th human bronchial passages. It has been reported that this is the region of the lung where pneumococcal pneumonia infections generally begin (37). Thus, using appropriate test bacteria, dosage regimes and aerosol deposition patterns which would be likely to be successful in treating developing lung infections could be determined before animal testing were undertaken. In this study, non-pathogenic E.coli MegaX DH10B ${ }^{\mathrm{TM}}$ T1R was used as a test bacterium to avoid the need for special containment requirements for working with human pathogens; however, it is envisaged that future tests with authentic pathogens will be carried out as necessary.

Using the lung model the dose-dependent efficacy of gentamicin and allicin aerosols against $E$. coli MegaX DH10B ${ }^{\mathrm{TM}}$ T1R was demonstrated (Figs. 9 and 10B and C). Furthermore, the model proved its potential for determining dosage regimes for bacteria exhibiting varying strengths of resistance to individual antibiotics (Fig. 10B and C). In these experiments, the $E$. coli strains used were isogenic apart from the $9 \mathrm{~kb}$ allicin resistance-conferring genomic clone from an allicin-resistant Pseudomonas fluorescens isolated from a garlic bulb (29). E. coli MegaX DH10B ${ }^{\mathrm{TM}}$ T1R transformants carrying this genomic clone exhibited increased allicin resistance, although both $E$. coli strains were equally susceptible to gentamicin. This situation is clearly recapitulated in the results of the aerosol dose-effectivity experiments shown in Fig. 10B and C, where it can clearly be seen that a larger dose of allicin was needed to achieve the same degree of inhibition of the resistant $E$. coli cells than the susceptible cells. By contrast, both strains responded equally to gentamicin. In this manner, treatment regimens tailored to individual resistance profiles of lung pathogenic bacteria might be optimized before progressing to animal trials.

Moreover, the potential of the model for highlighting synergism was demonstrated for ethanol and allicin in the gas phase (Fig. 11). Notably, the historical publication by Minchin which documents the use of garlic vapour to treat pulmonary tuberculosis in patient subjects, describes the preparation used for inhalation as ' $31 \frac{1}{2}$ ounces of succus allii sativi, $31 \frac{1}{2}$ drams sp. vini. and 1/2 dram of ol. eucalyp. Citriodora' (17). In contemporary measurements, this would be $98 \mathrm{~g}$ of garlic pulp, $13 \mathrm{ml}$ of ethanol and $1.85 \mathrm{ml}$ of eucalyptus oil. Minchin states that the ethanol helped to mask the garlic odour and preserved the garlic pulp during storage, whereas the eucalyptus oil was solely to mask the odour of the garlic. It is tempting to speculate that the ethanol in Dr Minchin's preparations might have had an unsuspected synergistic effect with allicin, similar to the one observed with the lung model in this study, and enhanced the inhibition of the mycobacteria in the lungs of his test subjects. The use of the lung model to test for synergism between allicin and other antibiotics, or other combinations of antibiotics not including allicin, is a promising aspect of the model's potential use.

There is certainly scope for future improvement and further development of the basic lung model test rig so that it can more closely resemble a real lung. For example, at present, the test rig only allows a continual uni-directional air-flow and does not simulate actual breathing during which air-flow accelerates, then slows to a minimum and reverses direction as air is exhaled. Incorporating such a breathing simulation pattern will be very desirable in the future to more accurately model the exposure pattern of bronchial surfaces to test substances. Other improvements could be surface coatings allowing growth of lung epithelial cells (38), with a long term view to co-cultivation with pathogenic bacteria for a more realistic simulation of the disease situation. Ideally, such cultivated epithelial cells would be continually supplied with blood and bathed with epithelial lining fluid (ELF), containing GSH in the $\mathrm{mM}$ range $(35,36)$. The technical difficulties which would need to be overcome for this near-natural situation will certainly not be trivial.

The present model could however, be easily adapted to be coated with growth medium which is seeded with fungal spores. With a suitable redox indicator, fungal growth inhibition by test substances could also be characterized using the test rig. Additionally, if test bacteria with a suitable bioluminescent reporter system were used to seed the agar coating the lung model surface, the quantitative response due to deposition of a test substance could be indicated in the different parts of the model and this would allow local deposition levels to be accurately determined. This information could also be used to design dosage parameters for any particular test substance as a prelude to animal experiments.

\section{Acknowledgements}

The authors would like to gratefully acknowledge Philipp Müller for Figs. 3, 4 and 6 and Ulrike Noll for the proofreading of the manuscript.

\section{Funding}

Financial support from the RWTH Aachen University (to JR, JB and AJS) is gratefully acknowledged. JR was supported by an RFwN Ph.D. stipendium.

\section{Availability of data and materials}

All data generated or analysed during this study are included in this published article or are available from the corresponding author on reasonable request.

\section{Authors' contributions}

JR, JB, PD, MK and contributed to the experimental work, data acquisition and analysis. AJS contributed to the conception and design of the experiments, data analysis and wrote the manuscript. MCHG and WS contributed to the conception of the study and critically revised the manuscript. All authors read and approved the final version of the manuscript. 


\section{Ethics approval and consent to participate}

Not applicable.

\section{Patient consent for publication}

Not applicable.

\section{Competing interests}

The authors declare that they have no competing interests.

\section{References}

1. Cavallito CJ and Bailey JH: Allicin, the antibacterial principle of Allium sativum. I. Isolation, physical properties and antibacterial action. J Am Chem Soc 66: 1950-1951, 1944.

2. Block E: Garlic and the other Alliums. The Lore and the Science (RSC Publishing), 2010.

3. Borlinghaus J, Albrecht F, Gruhlke MC, Nwachukwu ID and Slusarenko AJ: Allicin: Chemistry and biological properties. Molecules 19: 12591-12618, 2014.

4. Albrecht F, Leontiev R, Jacob C and Slusarenko AJ: An optimized facile procedure to synthesize and purify allicin. Molecules 22 pii: E770, 2017.

5. Cavallito CJ, Bailey JH and Buch J: Allicin, the antibacterial principle of Allium sativum. III. Its precursor and 'essential oil of garlic'. J Am Chem Soc 67: 1032-1033, 1945.

6. Rabinkov A, Miron T, Konstantinovski L, Wilchek M, Mirelman D and Weiner L: The mode of action of allicin: Trapping of radicals and interaction with thiol containing proteins. Biochim Biophys Acta 1379: 233-244, 1998.

7. Rabinkov A, Miron T, Mirelman D, Wilchek M, Glozman S, Yavin E and Weiner L: S-allylmercaptoglutathione: The reaction product of allicin with glutathione possesses $\mathrm{SH}$-modifying and antioxidant properties. Biochim Biophys Acta 1499: 144-153, 2000.

8. Miron T, Rabinkov A, Mirelman D, Wilchek M and Weiner L: The mode of action of allicin: Its ready permeability through phospholipid membranes may contribute to its biological activity. Biochim Biophys Acta 1463: 20-30, 2000.

9. Gruhlke MC, Hemmis B, Noll U, Wagner R, Luehring H and Slusarenko AJ: The defense substance allicin from garlic permeabilizes membranes of Beta vulgaris, Rhoeo discolor, Chara corallina and artificial lipid bilayers. Biochim Biophys Acta 1850: 602-611,2015.

10. Müller A, Eller J, Albrecht F, Prochnow P, Kuhlmann K, Bandow JE, Slusarenko AJ and Leichert LI: Allicin induces thiol stress in bacteria through S-Allylmercapto modification of protein cysteines. J Biol Chem 291: 11477-11490, 2016.

11. Reiter J, Levina N, van der Linden M, Gruhlke M, Martin C and Slusarenko AJ: Diallylthiosulfinate (Allicin), a volatile antimicrobial from garlic (Allium sativum), kills human lung pathogenic bacteria, including MDR strains, as a vapor. Molecules 22: pii: E1711, 2017.

12. Loi VV, Huyen NTT, Busche T, Tung QN, Gruhlke MCH, Kalinowski J, Bernhardt J, Slusarenko A and Antelmann H: Staphylococcus aureus responds to allicin by global $S$-thioallylation-role of the $\mathrm{Brx} / \mathrm{BSH} / \mathrm{Ypd}$ A pathway and the disulfide reductase MerA to overcome allicin stress. Free Radic Biol Med 139: 55-59, 2019.

13. Gruhlke MCH, Antelmann H, Bernhardt J, Kloubert V, Rink L and Slusarenko AJ: The human allicin-proteome: S-thioallylation of proteins by the garlic defence substance allicin and its biological effects. Free Radic Biol Med 131: 144-153, 2019.

14. Lawson LD and Hunsaker SM: Allicin bioavailability and bioequivalence from garlic supplements and garlic foods. Nutrients 10: pii: E812, 2018

15. Bjarnsholt T, Jensen PØ, Rasmussen TB, Christophersen L, Calum H, Hentzer M, Hougen HP, Rygaard J, Moser C, Eberl L, et al: Garlic blocks quorum sensing and promotes rapid clearing of pulmonary Pseudomonas aeruginosa infections. Microbiology 151: 3873-3880, 2005.
16. Smyth AR, Cifelli PM, Ortori CA, Righetti K, Lewis S, Erskine P, Holland ED, Givskov M, Williams P, Camara M, et al: Garlic as an inhibitor of Pseudomonas aeruginosa quorum sensing in cystic fibrosis-a pilot randomized controlled trial. Pediatr Pulmonol 45: 356-362, 2010

17. Minchin WC: A study in tubercle virus, polymorphism and the treatment of tuberculosis and lupus with Oleum alii. 3rd edition, Bailliere, Tindall \& Cox, London, pp110, 1927.

18. Sheppard JG and Long TE: Allicin-inspired fluoroquinolones as antibacterials against ESKAPE pathogens. Bioorg Medic Chem Lett 26: 5545-5549, 2016.

19. Högberg LD, Heddini A and Cars O: The global need for effective antibiotics: Challenges and recent advances. Trends Pharmacol Sci 31: 509-515, 2010

20. Ventola CL: The antibiotic resistance crisis: Part 1: Causes and threats. P T 40: 277-283, 2015.

21. Powers JH: Antimicrobial drug development-the past, the present, and the future. Clin Microbiol Infect 10 (Suppl 4): S23-S31, 2004

22. Silver LL: Challenges of antibacterial discovery. Clin Microbiol Rev 24: 71-109, 2011.

23. Muto CA, Jernigan JA, Ostrowsky BE, Richet HM, Jarvis WR, Boyce JM and Farr BM: SHEA guideline for preventing nosocomial transmission of multidrug-resistant strains of Staphylococcus aureus and Enterococcus. Infect Control Hosp Epidemiol 24: 362-386, 2003

24. Georg AM, Jones PM and Middleton PG: Cystic fibrosis infections: Treatment strategies and prospects. FEMS Microbiol Lett 300: 153-164, 2009.

25. Davies J and Davies D: Origins and evolution of antibiotic resistance. Microbiol Mol Biol Rev 74: 417-433, 2010.

26. Croucher NJ, Harris SR, Fraser C, Quail MA, Burton J, van der Linden M, McGee L, von Gottberg A, Song JH, Ko KS, et al: Rapid pneumococcal evolution in response to clinical interventions. Science 331: 430-435, 2011.

27. Dini C, Fabbri A and Geraci A: The potential role of garlic (Allium sativum) against the multi-drug resistant tuberculosis pandemic: A review. Ann Ist Super Sanita 47: 465-473, 2011.

28. Dörner P, Müller PM, Reiter J, Gruhlke MC, Slusarenko AJ, Schröder W and Klaas M: Feasibility of a surface-coated lung model for the quantification of active agent deposition for preclinical studies. bioRxiv: doi: 10.1101/639245.

29. Borlinghaus J, Bolger A, Schier C, Vogel A, Gruhlke MCH and Slusarenko AJ: Plant-microbe co-evolution: allicin resistance in a Pseudomonas fluorescens strain (PfAR-1) isolated from garlic. bioRxiv 769265. doi: https://doi.org/10.1101/769265.

30. Karunakaran R, Mauchline TH, Hosie AH and Poole PS: A family of promoter probe vectors incorporating autofluorescent and chromogenic reporter proteins for studying gene expression in Gram-negative bacteria. Microbiology 151: 3249-3256, 2005.

31. Leontiev R, Hohaus N, Jacob C, Gruhlke MCH and Slusarenko AJ: A comparison of the antibacterial and antifungal activities of thiosulfinate analogues of allicin. Sci Rep 8: 6763, 2018.

32. Horn T, Bettray W, Slusarenko AJ and Gruhlke MCH $\mathrm{S}$-allylmercaptoglutathione is a substrate for glutathione reductase (E.C. 1.8.1.7) from Yeast (Saccharomyces cerevisiae). Antioxidants 7: pii: E86, 2018.

33. Koch HP and Lawson LD: Garlic: The science and therapeutic application of Allium sativum L. and related species. Williams \& Wilkins, Baltimore, MD, 1996

34. Gruhlke MC, Nicco C, Batteux F and Slusarenko AJ: The effects of allicin, a reactive sulfur species from garlic, on a selection of mammalian cell lines. Antioxidants 6: pii E1, 2016.

35. Cantin AM, North SL, Hubbard RC and Crystal RG: Normal alveolar epithelial lining fluid contains high levels of glutathione. J Appl Physiol 63: 152-157, 1987.

36. Rahman I: Inflammation and the regulation of glutathione level in lung epithelial cells. Antioxid Redox Signal 1: 425-447, 1999.

37. van der Poll T and Opal SM: Pathogenesis, treatment, and prevention of pneumococcal pneumonia. Lancet 374: 1543-1556, 2009.

38. Lüngen AE, Bezela S, Kniebs C, Cornelissen CG, Jockenhoevel S and Thiebes AL: Differentiation and evaluation of respiratory epithelial cells on polycarbonate urethane nonwovens. Pneumologie 73: 117, 2019.

This work is licensed under a Creative Commons Attribution-NonCommercial-NoDerivatives 4.0 International (CC BY-NC-ND 4.0) License. 